\title{
Combined general anaesthesia in a horse with tricuspidal regurgitation and transthoracic sonographic monitoring of the cardiac function
}

\author{
Claudia Spadavecchia, Dagmar Trachsel, Peter Tschudi and Urs Schatzmann \\ Department of Clinical Veterinary Sciences, Vetsuisse Faculty, University of Bern, Switzerland
}

\begin{abstract}
Summary
A 7 years old colt was scheduled for routine castration. A 4/6 intensity holosystolic murmor was detected at thoracic auscultation during the preanesthetic examination. Transthoracic echocardiography confirmed the suspicion of tricuspidal valve regurgitation and did not reveal any other cardiac pathology. General anaesthesia was performed using a combined inhalation-intravenous protocol, with the horse in dorsal recumbency. Dobutamine was given at a low infusion rates, to maintain mean arterial blood pressure above $70 \mathrm{mmHg}$. During anaesthesia the cardiac function was repeatedly monitored using transthoracic ultrasonography. An improvement of cardiac contractility and only a small increase in the valve opening size could be detected while the horse was anaesthetized and dorsally recumbent.
\end{abstract}

Keywords: anaesthesia, cardiology, tricuspidal regurgitation, echocardiography

Kombinierte Allgemeinanästhesie mit sonographishem transthorakalem Monitoring der kardialen Funktion bei einem Pferd mit tricuspidaler Regurgitation

Ein 7-jähriger Hengst wurde für eine Routinekastration vorgestellt. Bei der Voruntersuchung für die Anästhesie fiel bei der Herzauskultation ein holosystolisches Geräusch der Intensität 4/6 auf. Die transthorakale Echokardiographie bestätigte den Verdacht einer Trikuspidalinsuffizienz und zeigte keine weiteren Veränderungen am Herzen. Das für die Allgemeinanästhesie in Rückenlage verwendete Protokoll bestand aus einer Kombination aus Inhalations- und Injektionsanästhetika. Eine langsame Dobutamininfusion erlaubte den mittleren arteriellen Blutdruck über $70 \mathrm{mmHg}$ zu halten. Wiederholte transthorakale Echokardiographie ermöglichten eine Überwachung der Herzfunktion während der Anästhesie. Diese Untersuchungen zeigten, trołz Anästhesie und Rückenlage, eine Verbesserung der Kontraktilität und nur eine geringradige Vergrößerung der Klappenöffnung.

Schlüsselwörter: Anästhesie, Kardiologie, Echokardiographie, Trikuspidalregurgitation, Regurgitation

\section{Introduction}

The relatively high perioperative mortality reported in horses when compared with other species has been primarily related to cardiac function impairment as a consequence of the anaesthetic procedure (Johnston et al. 1995). Cardiac depression and systemic hypotension are commonly observed and related to intraoperative and postoperative complications (Gillespie et al. 1969, Grandy et al. 1987, Lindsay et al. 1989). Cardiac murmurs of functional or pathological origin are frequently detected in horses (Patterson et al. 1965, Patteson and Cripps 1993, Marr and Reef 1995) but their clinical significance is strictly linked to the extent of valvular insufficiency and the presence of concomitant pathologic findings (Blissitt and Bonagura 1995a, Reef 1998). The use of M-mode, 2D and Doppler echocardiography allows to identify the form of valvular pathology, to semiquantitate the severity of regurgitation and to calculate indexes of cardiac performance (Stadler et al. 1994,VBonagura and Blissitt 1995, Blissitt and Bonagura 1995c, Blissitt and Bonagura 1995b, Blissitt and Bonagura 1995a, Stadler und Robine 1996, Reef 1998).

Tricuspid insufficiency not accompanied by other cardiac pathologies is quite commonly encountered in the horse, mostly in thoroughbred racehorses (Blissitt and Bonagura 1995a, Kriz et al. 2000). Physiological regurgitation associated with geometric changes of the right ventricle in response to hypertrophy have been proposed as possible causes (Young 1999, Young and Wood 2000). Apparently, age and degree of training play a role in the development of valvular incompetence. Horses with normal valve structure, moderate regurgitation and no signs of right ventricular overload have generally a good prognosis, since tricuspidal regurgitation is likely to remain unchanged throughout the life of the horse (Reef 1998).

\section{Case history}

In a horse with moderate tricuspidal regurgitation, not accompanied by other clinical signs, surgical castration had to be performed. A combined intravenous-inhalation protocol was used to maintain fifty minutes of general anaesthesia. The changes in the degree of tricuspid valve incompetence and left ventricular function before and during general anaesthesia were monitored by transthoracic echocardiography. 
Anamnesis and preanaesthetic assessment

A 7-years old trakkener colt, weighing $570 \mathrm{Kg}$, was presented for castration at the equine clinic of the University of Bern. The horse was fasted 12 hours before the time scheduled for the anaesthesia. At the preanaesthetic examination the heart rate was 32 beats/min, respiratory rate 12 breaths/min, mucous membrane color was pale pink, with a capillary filling time of 2 seconds. Though the cardiac cycle was rhythmic, a loud holosystolic murmur (grade 4/6) was detected at the auscultation of the right thoracic wall, with the point of maximal intensity located over the tricuspid valve area, radiating concentrically. Only a very weak murmur (1/6) was audible on the left side, at the level of the $2^{\circ}$ intercostal space. Jugular distension was absent. A tricuspidal closure defect was suspected and an echocardiography scheduled for preanaesthetic assessment of cardiac function.

For this examination the horse was restrained in stocks, unsedated, and hair was appropriately clipped. The ultrasonographic unit (Acuson $128 \mathrm{R} / \mathrm{F}$ ) was equipped with a $2.5-3.5 \mathrm{MHz}$ sector transducer for $B$ and $M$ imaging modes.

A scan from the right parasternal view was performed to evaluate right ventricle, tricuspidal valve, right atrium, intraventricular septum and aortic valve, but only the septal leaf of the mitral valve could be visualised. The long-axis and the shortaxis view were examined. The tricuspidal valve showed a deficient closure. The valve opening was of $328 \mathrm{~mm}^{2}$ over a total surface of $7391 \mathrm{~mm}^{2}$, meaning that $4,4 \%$ of the valve reminded open during the systole. A colour-doppler exam was performed over the 2D image where the regurgitation jet could be shown.

On the left side, the exam was continued for evaluation of the entire left ventricle and mitral valve. In the long-axis view, using a B-mode guided $\mathrm{M}$-mode echocardiography, the fractional shortening ( $F S=$ percentage of decrease of the LV minor axis) was calculated as an index of the left ventricular systolic function. A FS of $28,1 \%$ was found.

The echogardiographic exam confirmed the clinically suspected tricuspidal valve insufficiency, not accompanied by other pathological changes, except for a possible light decrease in myocardial contractility. Haematology and blood chemistry were normal.

Considering the favourable prognosis, the owner decided to proceed for castration.

\section{Anaesthetic management}

Six hours after the echocardiographic examination, the horse was premedicated intravenously with romifidin, $35 \mathrm{mg}$, and L-methadone, $30 \mathrm{mg}$. After catheter placement in the left jugular vein, anaesthesia was induced with an intravenous infusion of guaiphenesin $(30 \mathrm{~g})$, followed by ketamine $(1.3 \mathrm{~g})$. The trachea was intubated and the horse, placed in dorsal recumbency, was connected to the large animal circle system. Anaesthesia was maintained using isoflurane and $\mathrm{O}_{2}$ as the carrier gas. Simultaneously a continuos infusion of a mixture of ketamine $(6 \mathrm{mg} / \mathrm{ml})$ and guaiphenesin (150 $\mathrm{mg} / \mathrm{ml}$ ) was administered to reduce the amount of inhalation agent required, at a starting rate of $6 \mu \mathrm{l} / \mathrm{kg} / \mathrm{min}$. The infusion rate was then adjusted according to the horse requirement.

Routine monitoring was performed and consisted in the observation of the clinical signs of anaesthetic depth and continuous dispay of ECG, capnometry, end-tidal isoflurane concentration and arterial blood pressure. These parameters were recorded every 5 minutes for off-line analysis. For invasive blood pressure monitoring the left facial artery was cannulated. Arterial blood gas sampling and immediate analysis was performed at 15 minutes intervals. Dobutamine was infused to effect when the mean arterial blood pressure decreased under $70 \mathrm{mmHg}$, using a syringe pump.

Echocardiography was performed during anaesthesia to assess the eventual deterioration of cardiac function and tricuspidal regurgitation. For the examination in dorsal recumbency, it was tried to fulfill the same criteria as in standing position and it appeared possible to obtain a similar view. The tricuspidal opening area was of $378 \mathrm{~mm}^{2}$ corresponding to a $5,1 \%$ of the total valve surface. The FS was calculated at 10 minutes intervals during anaesthesia and it ranged between 39.5 and $44.2 \%$.

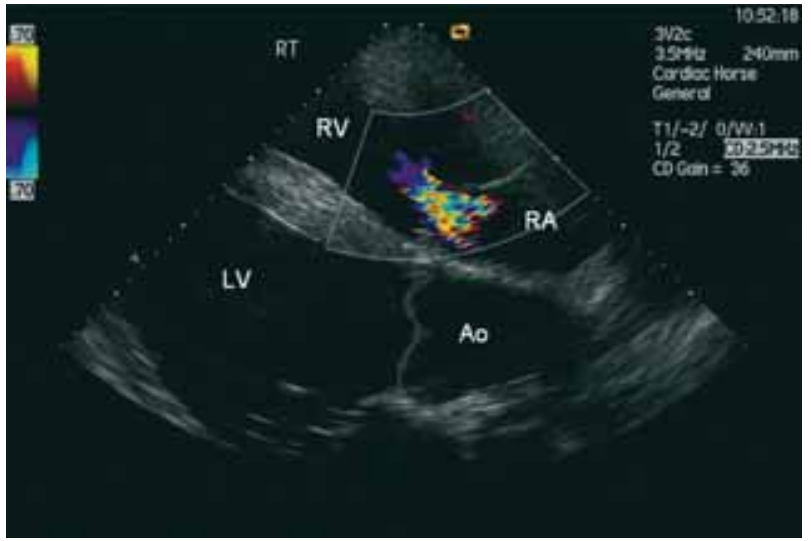

Fig 1 Right parasternal long-axis colour flow Doppler echocardiogram. A jet of tricuspidal insufficiency is present. LV: left ventricle, RV: right ventricle, Ao: aorta, RA: right atrium.

Echokardiographischer Längsschnitt des Herzens von der rechten Seite geschallt. Mit der Farbdopplertechnik ist eine Trikuspidalklappeninsuffizienz sichtbar. LV: linker Ventrikel, RV: rechter Ventrikel, Ao: Aorta, RA: rechter Vorhof.

General anaesthesia lasted 50 minutes. A stable anaesthetic plane was obtained with the combined intravenous-inhalation anaesthetic protocol. The horse breathed spontaneously throughout the anaesthetic procedure. No rise in heart rate or in arterial blood pressure associated with the surgical stimulation was detected. The end-tidal isoflurane concentration (ETiso) ranged from 1.1 to $1.4 \%$, while a total of $1 \mathrm{mg} / \mathrm{kg}$ ketamine and $20 \mathrm{mg} / \mathrm{kg}$ guaiphenesin were administered intravenously as adjunct to isoflurane anaesthesia. A mean dobutamine infusion rate of $8 \mathrm{mg} / \mathrm{kg} / \mathrm{hour}$ was necessary to keep mean blood pressure above $70 \mathrm{mmHg}$. Arterial blood gas analysis revealed a light progressive respiratory acidosis, with a $\mathrm{pH}$ decreasing from 7.30 to 7.25 at the end of anaesthesia and the partial pressure of $\mathrm{CO}_{2}\left(\mathrm{PaCO}_{2}\right)$ increasing from 51 to $62 \mathrm{mmHg}$. Partial pressure of oxygen $\left(\mathrm{PaO}_{2}\right)$ remained stable through the all procedure (range 330-410 $\mathrm{mmHg}$ ). 
At the end of the surgery, the isoflurane vaporizer was turned off and the infusions of ketamine and guaiphenesin stopped. Ten minutes after disconnection from the breathing circuit, the horse was extubated and assisted for the recovery. After a short sternal recumbency, he gained the standing position in a single attempt and only light ataxia was noticed in the following 15 minutes.

\section{Discussion}

For this horse, with a moderate tricuspidal regurgitation, an anaesthetic protocol with a minimal cardiac influence was selected: a balanced anaesthesia was performed, combining inhalation and intravenous drugs, to reduce the amount of each component and decrease the occurrence of dose-related side effects. In a previous clinical study, we showed that a combined inhalation-intravenous anaesthetic protocol was able to improve the stability of the anaesthetic plane and to lower the need for inotropes to maintain arterial blood pressure when compared with a pure inhalation protocol (Spadavecchia et al. 2002). Raisis et al. (2000) showed that left ventricular systolic function was better preserved with isoflurane when compared with halothane. Continuous infusion of ketamine throughout anaesthesia reduced inhalation agent requirements without depressing cardiac function and this is in line with the findings of Muir and Sams (1992)

In order to keep arterial blood pressure in a safe range, inotropic support was realised with dobutamine given to effect (Young et al. 1998, Gehlen et al. 2004). The mean infusion rate could be kept very low, showing that no strong cardiac support was needed.

The mean ETiso \% could be kept at values around 1 MAC, demonstrating the anaesthetic sparing effect obtained through the infusion of ketamine and guaiphenesin. The absence of reactions to surgical stimulation at this ETiso \% suggested efficient analgesic properties (Kohrs and Durieux 1998, Menigaux et al. 2000).

Transthoracic echocardiographic examination was also performed for monitoring of the cardiac function during anaesthesia. For this purpose a transesophageal technique could have been a good alternative (Young et al. 1995, Young et al. 1996, Reef 1998), but the visualization of the tricuspidal valve would have not be possible. Standard intracardial landmarks (Patteson et al. 1995, Patteson 1996, Reef 1998) were used to perform the measurements both preoperatively and intraoperatively, both in the standing position and in dorsal recumbency. Errors due to malpositioning could not be excluded, but the same experienced examiner performed both echocardiographies and a special care was taken to obtain comparable images.

The fractional shortening, as an index of left ventricular function (Reef 1998) was calculated on M-mode images from the left parasternal long axis view. The value of $28 \%$ found preoperatively possibly indicated a moderately reduced left ventricular systolic function. During anaesthesia this value increased to 39.5-44.2\%, demonstrating an improved cardiac contractility. Dobutamine and ketamine or their synergistic action could have contributed to this effect (Muir and Sams 1992, Young et al. 1998, Kohrs and Durieux 1998).

In order to determine the severity of the tricuspidal insufficiency the $\%$ of valve opening was calculated (Tschudi, personal communication 2000). The preoperative value of $4.1 \%$, considered to be at the limit of acceptabilty for a physiologic tricuspidal regurgitation, increased slightly during anaesthesia, to $5.2 \%$. Dorsal recumbency, changes in the diastolic filling of cardiac chambers or the slightly increased cardiac contractility could have been responsible for such an increase, which remained clinically irrelevant.

In conclusion, the echocardiographic transthoracic monitoring in a case of moderate tricuspidal regurgitation allowed to confirm a good maintenance of cardiac function and only a small increase in the valve openining during anaesthesia, using a combined intravenous-inhalation protocol. No signs of significant deterioration of valvular function were noticed and ventricular function improved of the pharmacological support, as observed on the basis of the standard clinical and instrumental monitoring performed.

\section{Literature}

Blissitt K. J. and Bonagura J. D. (1995a): Colour flow Doppler echocardiography in horses with cardiac murmurs. Equine Vet J Suppl, 82-85

Blissitt K. J. and Bonagura J. D. (1995b): Colour flow Doppler echocardiography in normal horses. Equine Vet J Suppl, 47-55

Blissitt K. J. and Bonagura J. D. (1995c): Pulsed wave Doppler echocardiography in normal horses. Equine Vet J Suppl, 38-46

Bonagura J. D. and Blissitt K. J. (1995): Echocardiography. Equine Vet J Suppl, 5-17

Gehlen H., Becker J., Deegen E. und Stadler P. (2004): Veränderung echokardiographischer Funktionsparameter unter Dobutaminwirkung bei Warmblutpferden mit und ohne Herzgeräusch. In: Vet. Med. Austria/Wien. Tierärztl. Mschr. 91, 103-111

Gillespie J. R., Tyler W. S. and Hall L. W. (1969): Cardiopulmonary dysfunction in anesthetized, laterally recumbent horses. Am J Vet Res 30, 61-72

Grandy J. L., Steffey E. P., Hodgson D. S. et al. (1987:) Arterial hypotension and the development of postanesthetic myopathy in halothane-anesthetized horses. Am J Vet Res 48, 192-197

Johnston G. M., Taylor P. M., Holmes M. A. et al. (1995): Confidential enquiry of perioperative equine fatalities (CEPEF-1): preliminary results. Equine Vet J 27, 193-200

Kohrs R. and Durieux M. E. (1998): Ketamine: teaching an old drug new tricks. Anesth Analg 87, 1186-1193

Kriz N. G., Hodgson D. R. and Rose R. J. (2000). Prevalence and clinical importance of heart murmurs in racehorses. J Am Vet Med Assoc 216, 1441-1445

Lindsay W. A., Robinson G. M., Brunson D. B. et al. (1989): Induction of equine postanesthetic myositis after halothane-induced hypotension. Am J Vet Res 50, 404-410

Marr C. M. and Reef V. B. (1995): Physiological valvular regurgitation in clinically normal young racehorses: prevalence and twodimensional colour flow Doppler echocardiographic characteristics. Equine Vet J Suppl, 56-62

Menigaux C., Fletcher D., Dupont X. et al. (2000): The benefits of intraoperative small-dose ketamine on postoperative pain after anterior cruciate ligament repair. Anesth Analg 90, 129-135

Muir W. W. III and Sams R. (1992): Effects of ketamine infusion on halothane minimal alveolar concentration in horses. Am J Vet Res 53, 1802-1806 
Patterson D. F., Detweiler D. K. and Glendenning S. A. (1965): Heart sounds and murmurs of the normal horse. Ann N Y Acad Sci 127, 242-305

Patteson M. (1996): Equine cardiology. 1st ed. Blackwell Science Ltd, Oxford.

Patteson M. W. and Cripps P. J. (1993): A survey of cardiac auscultatory findings in horses. Equine Vet J 25, 409-4 15

Patteson M. W., Gibbs C., Wotton P. R. et al. (1995) Echocardiographic measurements of cardiac dimensions and indices of cardiac function in normal adult thoroughbred horses. Equine Vet J Suppl, 18-27

Raisis A. L., Young L. E., Blissitt K. J. et al. (2000): A comparison of the haemodynamic effects of isoflurane and halothane anaesthesia in horses. Equine Vet J 32, 318-326

Reef V. B. (1998) Cardiovascular ultrasonography. In: VB Reef (Ed), Equine diagnostic ultrasound, pp. 215-272. W.B. Saunders Company, Philadelphia

Spadavecchia C., Stucki F., Moens Y. et al. (2002) Anaesthesia in horses using halothane and intravenous ketamine-guaiphenesin: a clinical study. Veterinary Anaesthesia and Analgesia 29, 20-28

Stadler P., Kinkel, N. und Deegen E. (1994): Ein Vergleich der Herzzeitvolumenbestimmung zwischen der Thermodilutionsmethode und der PW-Dopplerechokardiographie zur Beurteilung der systolischen Herzfunktion beim Pferd. Dtsch. tierärzłl. Wschr.101,312315

Stadler P und Robine F. (1996): Die Kardiometrie beim gesunden Warmblutpferd mit Hilfe der Schnittbildechographie im B-Mode. Pferdeheilkunde 12, 35-43
Young L. E. (1999) Cardiac responses to training in 2-year-old thoroughbreds: an echocardiographic study. Equine Vet J Suppl 30, 195-198

Young L. E., Blissitt K. J., Bartram D. H. et al. (1996) Measurement of cardiac output by transoesophageal Doppler echocardiography in anaesthetized horses: comparison with thermodilution. Br J Anaesth 77, 773-780

Young L. E., Blissitt K. J., Clutton R. E. et al. (1998): Temporal effects of an infusion of dobutamine hydrochloride in horses anesthetized with halothane. Am J Vet Res 59, 1027-1032

Young L. E., Blissitt K. J., Clutton R. E. et al. (1995): Feasibility of transoesophageal echocardiography for evaluation of left ventricular performance in anaesthetised horses. Equine Vet J Suppl, 63-70

Young L. E. and Wood J. L. (2000): Effect of age and training on murmurs of atrioventricular valvular regurgitation in young thoroughbreds. Equine Vet J 32, 195-199

Dr. Claudia Spadavecchia, PhD, Dipl ECVA

Norwegian School of Veterinary Science

Dept. of Companion Animal Clinical Sciences

Postboks 8146 Dep.

0033 Oslo

Norwayclaudia.spadavecchia@veths.no
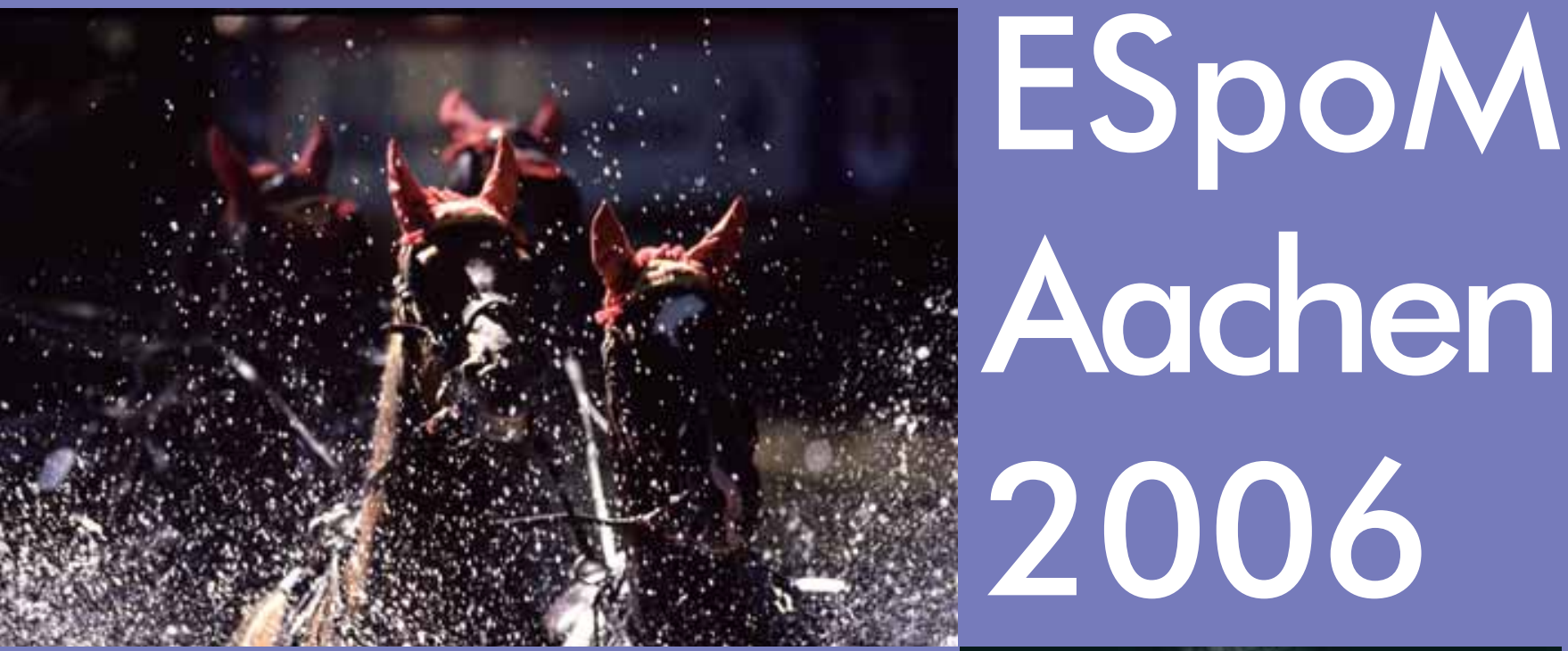

Int. Kongress für Tierärzłe und Hufschmiede 23.-26. August 2006, Aachen während der FEI Weltreiterspiele

\author{
20 Seminare, 65 Vorträge, Posterausstellung \\ große Fachmesse, Dressurfinale
}

www.espomadchen2006.info
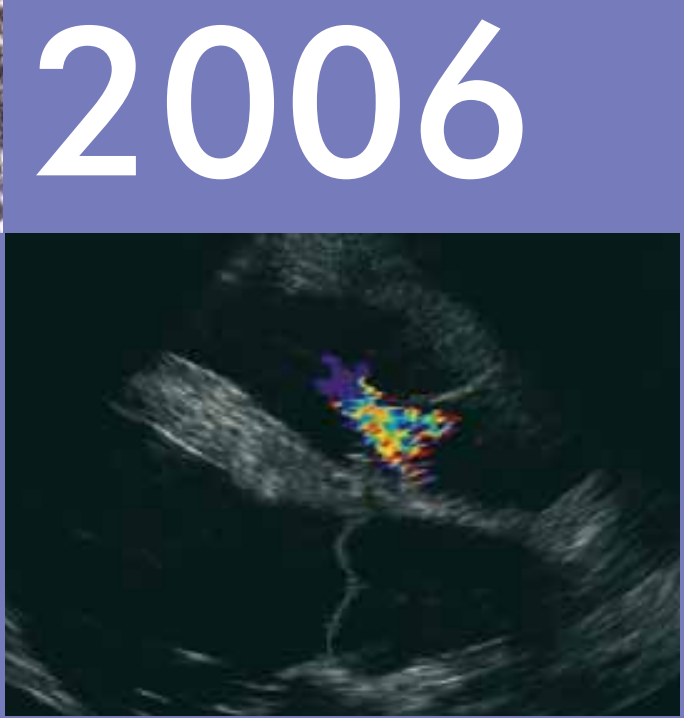